DOI: $10.17805 /$ trudy.2018.2.6

\title{
ПРОБЛЕМА ДРУГОГО В СОВРЕМЕННЫХ СОЦИАЛЬНО-КУЛЬТУРНЫХ ПРАКТИКАХ
}

\author{
С. Е. Крючкова \\ Национальный исследовательский университет - \\ Высшая школа экономики, г. Москва
}

Аннотация: В статье исследуется эвристический потенциал феноменологии Э. Гуссерля для решения проблемы Другого (другого Я), которая имеет важное значение для построения общей теории аргументации.

Текст доклада автора на Всероссийской научной конференции «Культура между Логосом и Мифом: к проблеме бессознательного (к 80-летию А.Э. Воскобойникова)», которая прошла в Московском гуманитарном университете 26-27 октября 2017 года.

Ключевые слова: теория аргументации; феноменология, субъект; Другой; социокультурные практики

\section{THE ISSUE OF ANOTHER IN MODERN SOCIAL AND CULTURAL PRACTICES}

\author{
S. E. Kryuchkova \\ National Research University - Higher school of Economics
}

Аннотация: This article examines the heuristic potential of E. Husserl's phenomenology to resolve the issue of Another (alter ego), which is important for building a general theory of argumentation.

The text of the author's speech at the All-Russian Scientific Conference "Culture between Logos and Myth: on the Issue of the Unconscious (dedicated to the 80th anniversary of A. E. Voskoboynikov)", which was held at Moscow University for the Humanities on 26-27 October 2017.

Ключевые слова: argumentation theory; phenomenology; subject; Another; social and cultural practices

Одна из классических интуиций Нового времени - картезианская интуиция $Я$, активно обсуждавшаяся в культуре позднего Просвещения, получила неожиданное и специфическое развитие в культурологических и философских построениях $\mathrm{XX}$ века в форме дихотомии $Я$ - Другой. Идея Я изначально с неизбежностью порождала идею Alter Ego, другого Я (Другого), который конституирует субъектность $Я$, т. к. человек начинает относится к 
Научные труды Московского гуманитарного университета 2018 № 2

себе как к «человеку», только лишь тогда, когда смотрится в Другого, как в зеркало. Проблема Другого в целом ряде направлений неклассической философии постепенно вышла на первый план: Другой из парной периферийной категории, долго находившейся «за спиной» $Я$, вышел на авансцену.

Сегодня тема Другого все более мощно звучит в теоретических исследованиях современной медиатизированной культуры. Медиаобразы Другого «становятся факторами, конструирующими «реальность» для медиаудитории, охватившей практически весь земной шар. Их производство происходит в соответствии с законами потребительского общества и культурной индустрии» (Шапинская, 2012: 5). Это поднимает проблему Другого на уровень социальной значимости. Как следствие, проблематизация Другого осуществляется и в академическом дискурсе, и в разных формах популярной культуры. Особое место «в поисках Другого» принадлежит таким философам как Э. Гуссерль, К. Ясперс, М. Бубер, Ж.-П. Сартр, А. Камю, Г. Марсель, М. Хайдеггер, Э. Левинас и др.

Источник исследовательского интереса к проблеме Другого, и в целом к онтологии субъекта, следует искать в характере современной культуры, в коммуникативном пространстве которой возник целый ряд проблем, связанных с кризисом идентичности, а следовательно, и с поиском возможностей сохранения автономным субъектом своей «друговости», которая продолжает оставаться привилегией, за которую надо бороться, чтобы утвердить не только свое право на отличие, но и право на «инаковость Другого» (Э. Левинас).

В современной культуре одной из наиболее значимых социальных практик является коммуникация, т. к. только «общаясь люди создают друг друга» (Д. Лихачев). Сама духовная культура «есть форма одновременного бытия и общения людей» (Библер, 1991: 290). Культура живет в диалоге, который в этом смысле может быть представлен как путь к пониманию Другого. Диалоговые формы коммуникации Я и Другого, как равноправных субъектов, актуализируют значение аргументативного дискурса, как средства манифестации и обоснования участниками диалога своей позиции. Именно аргументация чаще всего выступает как та область пространства культуры, в которой осуществляется взаимодействие субъективных носителей сознания, что в определенной степени сближает ее с герменевтикой, в той части, где последняя исследует «невместимый в пределы одного сознания» интерсубъективный смысл (М. Бахтин).

Чтобы диалог (межличностный и межкультурный) состоялся, его участники должны иметь некий общий базис, некоторое общее поле аргументации, которое формируется на основе представления субъектами диалога внутренних миров, психологии друг друга. «Аргументация всегда, во-пер- 
вых, направлена на некоего субъекта, выступающего в роли «объекта аргументации», во-вторых, она носит в силу своей философско-мировоззренческой природы, субъективированный характер, и, в-третьих, она исходит из определенного субъекта, сколь бы «генерализированным» (отдельный человек, группа, общество, эпоха и т. д.) он не был» (Ольшанский, 1986: 405). Только в случае учета индивидуальных особенностей участников, их ценностных установок и моделей мира, диалог в принципе становится возможным, а убеждающее речевое аргументативное воздействие продуктивным.

Но как реально осуществлять такой учет? По-видимому, необходима предварительная диагностика аргументатором мысленного поля адресата. Это ставит перед исследователями задачу выявления того, каким образом формируется представление о внутреннем мире Другого. Такая постановка вопроса имеет глубокие философские основания, их выявлением в прошлом столетии занялась феноменология, манифестировавшая в качестве своей цели разработку интерсубъективной программы обоснования человеческого мышления.

Так Э. Гуссерль в своей знаменитой работе «Философия как строгая наука» исходит из установки теоретической непредвзятости. Отказавшись от традиционной схемы субъект-объектного отношения, он придает основную значимость концептам трансцендентального Эго (Я в отличие от Другого). Теоретическая рефлексия над феноменом аргументации вне использования классических понятий субъекта и объекта в ситуации аргументативного диалога начинается в данном случае с исследования вопроса о том, «как я могу конституировать в себе другое Я» (Гуссерль, 2010: 162). Центрирование Я в данном случае не означает игнорирование Другого, оно, наоборот, приближает к нему в силу того, что Другой подобен Я. Это означает, что эгологическая феноменология сохраняет значимость для любого еgо вообще, а значит, и Другого.

Появление феноменологической концепции Другого явилось попыт-кой нахождения нового «угла зрения» на стратегию субъектов в аргументативном дискурсе. Такой подход позволил сконцентрироваться на решении задачи выявления механизмов, связанных с планированием и созданием субъектом-аргументатором убеждающей речи. Такая речь в обязательном порядке обязана включать личностные смыслы, которые субъект-аргументатор нацелен передать Другому, а последний, в свою очередь, должен понять и (в идеале) принять его точку зрения.

Очевидно, что для изменения точки зрения Другого аргументационная речь должна носить адресный характер. Обеспечению этой «адресности» и служит «диагностика» Другого, позволяющая в итоге проникнуть в его личный ментальный мир, обычно закрытый от внешней среды. Пред- 
Научные труды Московского гуманитарного университета 2018 № 2

варительная «диагностика» позволит понять, соприкасаются ли личностные смысловые пространства субъектов - участников аргументации и в какой степени? Каков же когнитивный механизм такой «диагностики»? Прояснение этого вопроса, оказавшегося в фокусе исследовательского интереса феноменологии, представляется весьма продуктивным для теории аргументации. Наряду с концепцией Другого, для ее создания также важно рассмотрение проблем интерсубъективности и смысла, которые исследовались в работах Э. Гуссерля, а также претендовавшей на универсализм в «коммуникативной программе» К.-О. Апеля и Ю. Хабермаса, разработавших интерсубъективую программу обоснования человеческого мышления.

Подвергнув отрицанию принципы старой метафизики, Э. Гуссерль, тем не менее, на деле не отказался от использования ее некоторых положе-ний. Так он использует из ее эпистемологического багажа (при этом, конечно, теоретически переосмысливая) концепт «трансцендентальное Эго». Субъект Э. Гуссерля - это Я, взятое вместе с чистой жизнью его сознания, в которой (и благодаря которой) существует весь объективный мир, и существует именно для этого Я (Гуссерль, 2006: 77). Полагая трансцендентального субъекта аподиктическим принципом своей теории, Э. Гуссерль видит его и источником смыслов предметностей. Другой для него также выступает как предметность, но это - трансцендентальная предметность особого рода. «Сфере моего душевного бытия принадлежит все конституирование существующего для меня мира, а кроме того, разделение этого конституирования на конститутивные системы, которые конституируют специфически собственное и Чужое» (Гуссерль, 2010: 127).

Для Э. Гуссерля начало пути к Другому Я лежит в первичной смысловой сфере Я, очищенной от «естественной установки» обыденного мышления, согласно которой вещи рассматриваются как самостоятельные «данности». Именно это традиционное представление, по его мнению, прочно укоренилось в нашем сознании, вследствие чего оно и явилось одной из причин объективизма картезианской рационалистической традиции. Ситуация, когда «почерпнутое из опыта сразу же получало для меня значимость, и это было базисом для всех остальных моих точек зрения» (Гуссерль, 1991: 14), по мнению Э. Гуссерля, должна быть преодолена в ходе освобождения сознания от объективистских иллюзий.

Э. Гуссерль исследует вопрос о том, как Я может признавать независимое существование других сознаний, и, следовательно, как можно проникнуть в ментальное, смысловое пространство Другого, если оно не может быть предметом восприятия? Другой не дан непосредственно, т. к. «если бы имело место обратное, если бы то, что по своей сущности свойственно Другому, было доступно непосредственно, то оно было бы лишь моментом 
моей собственной сущности, и в конечном счете, он сам и я сам были бы одним и тем же» (Гуссерль, 2010: 140), включая и телесность. Однако, существование Другого, как заметит позднее Ж.-П. Сартр, очевидно не только на теоретическом уровне, но и на эмоциональном, о чем свидетельствуют испытываемые под взглядом Другого такие чувства как смущение, стыд и др. («Ад - это другие»).

В попытке избежать трансцендентального солипсизма, а также решая свою глобальную задачу обоснования феноменологической науки, как универсального общезначимого метода, Э. Гуссерль ставит цель - обосновать существование других $Я$, как трансцендентальных субъектов. Техническое решение этой задачи оказалось весьма непростым. Сначала с помощью метода феноменологической редукции он отказывается от присутствия Друго20, как некоей изначальной данности, а затем при обращении к феноменам, он осуществляет своего рода «удвоение» трансцендентальных субъектов, где Другой выступает в форме интенциональной модификации.

По мнению Э. Гуссерля, опыт по признанию и обоснованию Другого происходит с помощью метода аппрезентативно-апперцептивного переноса, весьма напоминающего, по мнению ряда исследователей, аналогию. При этом философ считает, что данная процедура есть «определенного рода уподобляющая апперцепция, а потому никоим образом не заключение по аналогии. Апперцепия не логический вывод, не акт мышления» (Гуссерль, 2010: 143). Она позволяет с первого взгляда постигать смысл предданнго повседневного мира «вместе с его горизонтами, интенционально отсылает к некоторому первичному установлению (Urstftung), в котором предмет, имеющий подобный смысл был впервые сконструирован» (там же). А вот затем уже в повседневном опыте осуществляется собственно аналогизирующий перенос первоначально установленного предметного смысла на новый случай, своего рода типизация. Так обнаруживая другое, подобное моему, тело, полагает Э. Гуссерль, Я благодаря ассоциации, образующей пару с моим «живым телом», приписываю ему и душу, т. е. признаю за ним свойство быть психо-физическим «живым телом», то есть другим Я. Таким образом, в интенциональных данных $Я$ конституируются данные опыта Другого. Так появляется другая субъективность, для которой тоже есть другие, составляющие сообщество трансцендентальных Эго, состоящее из своеобразных периферийных монад, центрирующееся вокруг Я. Эти монады могут общаться, сообщая друг другу, что происходит в их трансцендентальных мирах, обогащая при этом друг друга. Сообщество монад немецкий философ, по сути, интерпретирует как человеческое сообщество, в котором в результате общения в соответствие приводятся субъективные времена и пространства. В конечном результате «мой мир» становится интерсубъ- 
Научные труды Московского гуманитарного университета 2018 № 2

ективным, в него включается как природа, так и социум. Таким образом, исследуя ментальное пространство интенциональных актов $Я$, Гуссерль решает проблему нахождения интерсубъективности, конституируя тем самым новый смысл бытия.

Осуществляя «перенос достоверности» с собственного монадического сознания, на Другого, можно понять, как его сознание конструирует смысл предметности. При этом Другой - это проекция меня самого, но не как моя копия, не как продукт конститутивной деятельности Я, а как Другое (чужое) Я. Без проникновения в сознание Другого никакая коммуникация, взаимопонимание и аргументация невозможны. Способом такого проникновения может выступать только экстериоризация собственных ментальных состояний, «овнешнение», в ходе которого «человек, образно говоря, «выворачивает себя наизнанку», вынося свой внутренний мир наружу и делая его, таким образом, доступным для контакта с другим человеком», позволяя «соприкоснуться «внутренними поверхностями», сопоставить ментальные состояния» (Липский, 2011: 21). А следовательно, не только вступить в коммуникацию, но и в конечном счете, узнать с помощью «вчувствования», стали ли смыслы Я понятны Другому, приняты ли они во внимание, т. е. получить ответ об успешности/неуспешности аргументации. Именно понятие смысла, как интерсубъективности, погруженной в субъективность, позволяет с помощью феноменологического метода Э. Гуссерля иначе взглянуть на некоторые «догмы» теории аргументации, связанные с таким необходимым условием успешной аргументативной речи, как ее адресность, основанная на максимальном учете личностных характеристик Другого, в данном случае субъекта-адресата.

Однако, вряд ли возможно, даже с помощью изощренного теоретического анализа, используемого феноменологами, осуществить доскональную диагностику Другого, проникнуть в самые глубины его личности. Тем не менее, факт успешных аргументаций свидетельствует о том, что какимто образом путь к смыслам Другого находится. Примерами могут служить многочисленные случаи убеждающего воздействия художественных текстов («над вымыслом слезами обольюсь») или выступлений знаменитых ораторов перед толпой.

Объективирующая методология, отвлекающаяся от субъективного измерения адресата, практически всегда тяготеет к когнитивному «бегству от смысла». Вместе с тем, без учета последнего сложно объяснить, почему «анонимные» аргументационные речи, рассчитанные на широкую аудиторию, не отвечающие требованию учета индивидуальности адресата, особенностей его восприятия, тем не менее, бывают неожиданно более успешны, чем даже те, которые императив адресности соблюдают. 
Используя гуссерлевскую идею о механизме смыслообразования, данному эффекту «резонанса в целое» (Т. де Шарден) можно дать объяснение с позиции феноменологического подхода. Последний вполне успешно, как показали Д. В. Зайцев и Н. В. Зайцева, может быть применен как средство анализа и интерпретации эффекта встраивания смысла в концептуальную систему субъекта в ходе аргументации. На конкретных и весьма разнородных примерах (библейской притчи о книжниках и фарисеях, речи адвоката Ф. Н. Плевако, а также пушкинского стихотворения «Зимнее утро») ими было выявлено, каким образом, избежав подробностей, связанных с личным восприятием, достигается потрясающий эффект «узнавания» и «сопереживания». «Во всех трех примерах парадоксальным образом, жертвуя адресностью, авторы добиваются эффекта интерсубъективности транслируемого смысла... именно благодаря «анонимности» сообщения, адресату оказывается просто встроить транслируемый смысл в свою концептуальную систему, преобразовать интерсубъективный, объективный смысл сообщения в личный, субъективный смысл» (Зайцев, Зайцева, 2006: 111). Этот же механизм присутствует в аргументации, когда в ходе полемики каждому из субъектов приходится оценивать информацию с позиции своего личного опыта.

Таким образом, понятие интерсубъективности смысла, связанное с идентичностью сонаправленных интенциональных актов субъектов, взятое в качестве принципа, объясняет, почему при отсутствии высокой степени адресности той или иной аргументативной речи, она часто успешно встраивается в личный смысловой мир субъекта-адресата. Вместе с тем, вопрос о передаче смысла превращается в вопрос об условиях понимания, интерпретации опредмеченных смыслов, содержащихся в культуре.

Э. Гуссерль, отмечая существование отдельных сообществ, также не обошел вниманием роль культуры, подчеркивая, что «природа для всех одна, а культуры разные». Понять культуру Другого (Я и моя культура являются для него перовопорядковыми) можно, подчеркивает он в «Картезианских размышлениях», методом вчувствования. Это позволяет осуществить, во-первых, процесс понимания смысла Другого, а во-вторых, транслировать свой смысл Другому, сделать свой смысл смыслом Другого. Именно это обеспечивает успех аргументации, так как субъект адресат воспринимает интерсубъективные смыслы не как внешние и навязанные, а как свои собственные, т. е. согласующиеся и соответствующие его индивидуальному опыту. Интерсубъективизм в этом смысле является своего рода залогом эффективной аргументации.

Таким образом, в ходе произведенной Э. Гуссерлем трансцендентально-феноменологической редукции была снята «жесткая» субъектно-объ- 
Научные труды Московского гуманитарного университета 2018 № 2

ектная дихотомия: Другой оказался «проекцией меня самого», а следовательно, он изначально встроен в структуры «самости» субъекта, «присутствует в горизонте сознания личности даже в ситуации беспросветного одиночества или затерянности в толпе» (Смирнова, 2011: 129).

Вместе с тем, в ходе феноменологической редукции «очистился»не только внутренний опыт субъекта, но и были вынесены «за скобки» окружающий мир (природа, культура, социум) и само эмпирическое $Я$ (со всей его психической жизнью). Из-за такого сугубо умозрительного подхода трансцендентальный субъект Э. Гуссерля получился «слишком абстрактным, безличным, лишенным каких бы то ни было особенностей; он представляется не более чем точкой, из которой исходят интенциональные акты» (Слинин, 2000: 315). Лишенность же Другого каких бы то ни было личностных характеристик, в свою очередь, ставит под сомнение возникновение и существование у $Я$ желания и потребности с ним общаться. Таким образом, «очищение» внутреннего мира субъекта, доведенное до некоторого логического конца, может привести к исчезновению самой потребности в коммуникации, а следовательно, и в аргументации любого рода.

Гуссерлевское понимание $Я$ наделено полнотой теоретического сознания в ущерб душевной жизни, что не позволяет ему полностью пролить свет на трансцендирование, на личностный способ бытия $Я$ «лицом-к-лицу» с Другим. Вместе с тем, неверно было бы утверждать, что Э. Гуссерль вообще никак не учитывает индивидуально-психологические (субъективные) и специфические познавательные характеристики сознания субъекта, имеющие важное значение в ситуации убеждения. К примеру, он вводит понятие «жизненного мира», как личностного мира», включающего убеждения, интересы, привычки, семью, страну и т. д., т. е. связывает субъективность с личностью. «Жизненный мир» окружает Я в течение его жизни, за ним в отдалении выстраивается вырастающий из этого мира второй мир мир культуры. Интерсубъективность связывается им с языком, носителем которого является «со-человечество», как «сообщество общающихся друг с другом людей». Мир культуры выступает интерсубъективной средой, в которой конституируются разные личностные и социальные смыслы. Наличие последних подпитывает потребность не только в коммуникации, как таковой, но и стимулирует убеждающее общение, в ходе которого мы встречаемся с примерами ар-гументации.

Понятие глобальной этики актуализирует для современности понятия «Другого как своего» и «Другого как чужого» в культуре. К сожалению, фигура Другого в эпоху глобализации все чаще приобретает образ Чужого, причем последний в случае социальных столкновений рассматривается, как правило, в качестве противника с соответствующими негативными ха- 
рактеристиками. При этом упускается из виду важное обстоятельство, что в разных культурах существуют весьма тонкие, специфические, осознаваемые всеми традиции социального дистанцирования, т. е. понятия «Свой» (близкий) и «Чужой» (иной) весьма различаются. То, что приемлемо для одной культуры или для одних социальных групп, отвергается другими. Надо принять, что все мы Другие, каждый есть Иное по отношению к Иному.

Сегодня на повестке дня по-прежнему стоит задача преодолеть «непреодолимую аллергию по отношению к Другому, остающемуся «Другим» (Э. Левинас). Опасность конфронтации, порождаемой таким аллергическим отношением ко всякому отличию, выражающемуся дихотомией «Свой-Чужой» приводит все большее число людей к осознанию того, что выход из кризисных ситуаций возможен лишь путем диалога, как между отдельными людьми, так и между культурами, странами и цивилизациями. Толерантность, как умение притираться друг к другу, несмотря на «неустранимые шероховатости» (М. Хайдеггер), как принятие инаковости Другого, а не стремление его ассимилировать, не оставляя шансов на сохранение его инаковости, - необходимое условие диалога.

\section{СПИСОК ЛИТЕРАТУРЫ}

Библер, В. С. (1991) От наукоучения - к логике культуры. Два философских введения в XX век. М.: Политиздат.

Гуссерль, Э. (1991) Парижские доклады // Логос. № 2. С. 6-30.

Гуссерль, Э. (2006) Картезианские размышления / пер. с нем. Д. В. Скляднева. СПб.: Наука.

Гуссерль, Э. (2010) Картезианские медитации / пер. с нем. В. И. Молчанова. М.: Академический проект.

Зайцев, Д. В., Зайцева, Н. В. (2006) Мороz и солнце. Интерсубъективность в аргументации // Мысль. Ежегодник С.-Петербургского философского общества. № 6 (Аргументация).

Липский, Б. И. (2011) Вещь как интенциональный объект // Вопросы философии. № 2. С. 14-22.

Ольшанский, Д. В. (1986) Проблема психологических механизмов аргументации // Философские проблемы аргументации. Ереван.

Слинин, Я. А. (2000) Гуссерль и его «Картезианские размышления // Гуссерль Э. Логические исследования. Картезианские размышления. Мн.: Харвест, М. : АСТ.

Смирнова, Н. М. (2011) Эпистемология жизненного мира: новые ко-гнитивные горизонты // Эпистемология: новые горизонты. М.: «Канон+» РООИ «Реабилитация». 
Шапинская, Е. Н. (2012) Образ Другого в текстах культуры. М.: КРАСАНД. Дата поступления: 12.12.2017 2.

Крючкова Светлана Евгеньевна - доктор философских наук, профессор Школы философии факультета Гуманитарных наук Национального исследовательского университета - Высшая школа экономики. Адрес: 101000, Россия, г. Москва, ул. Мясницкая, д. 20. Тел. +7 (495) 772-95-90, доб. 22685. Эл. адрес: Skryuchkova@hse.ru

Kryuchkova Svetlana Evgenyevna, Doctor of Philosophical Sciences, Professor of the School of philosophy, faculty of Humanities, National research University - Higher school of Economics. Postal address: Moscow, 20 Myasnitskaya str. Tel.: +7 (495) 772-95-90 ext. 22685. E-mail: Skryuchkova@hse.ru

\section{Для цитирования:}

Крючкова С. Е. Проблема Другого в современных социально-культурных практиках [Электронный ресурс] // Научные труды Московского гуманитарного университета. 2018. №2. URL: http://journals.mosgu.ru/trudy/ article/view/693 (дата обращения: дд.мм.гг.). DOI: 10.17805/trudy.2018.2.6 